\title{
Views of the taught and the teachers on medical ethics teaching in two universities in Kenya
}

\author{
ELIZABETH ANNE BUKUSI
}

\begin{abstract}
Medical or clinical ethics provides guidance for health practitioners and has, hopefully, been taught to medical students during training. The teaching of clinical/medical ethics is more important in the current times because of advances in medical science and the different cultural and socioeconomic circumstances in which medicine is practised. This study sought to determine if and how clinical/medical ethics was taught at two Kenyan medical schools by conducting focus group discussions with undergraduate students and key informant interviews with lecturers teaching ethics and academic administrators. While medical/clinical ethics is a part of the medical curriculum approved by the Kenya Medical and Dental Practitioners Council (Board) and is taught during the training, we identified a gap between the theory and application of ethics education. Undergraduates, medical school administrators and lecturers from both institutions acknowledged a lack of role models and mentors, and a need for further training in communication skills since medical ethics has not been made an examinable subject and there has been no formal requirement for training of lecturers teaching ethics. For the short-term, these gaps can be addressed by training lecturers in medical/clinical ethics, and identifying and utilising suitable reference materials, while long-term measures include developing context-appropriate materials for teaching, in addition to nurturing mentorship skills among lecturers for ethical role modeling.
\end{abstract}

Keywords: medical (clinical) ethics, medical training, ethical behaviour, undergraduate medical students

Authors: Elizabeth Anne Bukusi (ebukusi@kemri.org), Senior Principal Clinical Research Scientist, Centre for Microbiology Research, Kenya Medical Research Institute, Nairobi, KENYA.

To cite: Bukusi EA. Views of the taught and the teachers on the medical ethics teaching in two universities in Kenya. Indian J Med Ethics. Published online first on February 26, 2022. DOI: 10.20529/IJME.2022.017

Manuscript Editor: Vijayaprasad Gopichandran

Peer reviewers: Two anonymous peer reviewers.

Copyright and license

(C) Indian Journal of Medical Ethics 2022:Open Access and Distributed under the Creative Commons license CC BY-NC-ND 4.9, which permits only non-commercial and non-modified sharing in any medium, provided the original author(s) and source are credited.

\section{Introduction}

Medical or clinical ethics provides codes of conduct for healthcare professionals [1]. These include responsibilities and expectations. Such principles guide every day practice for medical care, but more importantly for the resolution of medical dilemmas.

Modern medicine is traced back to the "father of medicine" Hippocrates (460-375 BCE), and this is signified in the Hippocratic Oath [2] which is still administered in some form to graduating medical doctors. While the relevance of this traditional oath has been questioned, the need for a professional code of ethics or standards [3] is clear. The core of medical practice is the doctor-patient interaction [4] and the fiduciary responsibly therein. Several factors influence this relationship, and in this complex inter-play the vital role of (bio)ethics and professionalism in medical practice is selfevident.

The Kenya Medical Practitioners and Dentists Board (KMDB) was set up under the laws of Kenya to regulate medical practice [1], and after an amendment in 2019, it is known as the Kenya Medical Practitioners and Dentists Council (KMPDC) [1]. Its core mandates include the regulation of training of medical and dental practitioners including approval of institutions offering training and review of the curriculum, registration, and renewal of registration for both training institutions and medical practitioners. The code of ethics provided by the Kenya Medical and Dental Practitioners' Board [1] lays out the responsibilities of the board that include registration, licensure of individual practitioners and accreditation of institutions that teach medical doctors and dentists, and dealing with professional misconduct. The code of professional conduct and discipline, revised by the Kenya Medical and Dental Practitioners Board in January 2012 [5], does not explicitly mention new and emerging medical advances, or relations with the pharmaceutical industry. The code discusses relationships between doctors and the public, colleagues, and what is expected in terms of human rights of the patients and what to do when there is a conflict of interest. As with all codes, the implementation remains a challenge. One such challenge is the difficulty in implementing patient privacy, especially in resource-limited settings where patients may sometimes share a hospital bed.

The KMDB approved curriculum [6] includes medical ethics 
to be taught in medical schools. The exact mode of teaching is determined by the university as the university submits its curriculum to Kenya's Commission of University Education [7] for approval and accreditation. The details of how the teaching of medical ethics is implemented has never been studied previously. Therefore, this study sought to evaluate the teaching of ethics to undergraduates in the two oldest medical schools in Kenya. These schools are the University of Nairobi (UoN) and the Moi University School of Medicine.

The KMDB provides admission criteria for all medical courses [6]. The current course duration is 6 years with the first three years considered as pre-clinical and the final years as clinical years. The council requires medical schools to define the instructional methods that encompass diverse teaching and learning approaches. In addition, the minimum credit hours required for a unit course - are 15 hours of lectures, 30 hours of tutorials and 45 hours of practicals. The programme is weighted as a total of 220 units over the 6 years of training. One unit of the medical course is equivalent to one week of teaching. In the pre-clinical years, the courses that discuss ethics include Behavioural and Social Sciences (Anthropology, Sociology and Psychology) - a total of 3 units, and Communication Skills for health workers - an additional 3 units. During the senior clerkship, medical ethics, professional conduct and medico-legal issues are allocated a total of 3 units [6]. Thus, a total 9 out of the 220 units include some focused element of ethics, over 6 years of learning.

Currently, 11 medical schools have been approved [8] by Kenya's Commission for University Education. The University of Nairobi and Moi medical schools were the first schools to be set up and have trained the largest number of medical practitioners, including many who have gone on now to teach in the more recently established medical schools.

The current practice of medicine is fraught with new and emerging challenges because of the advancement of science, thereby increasing the urgent need for training [9] in medical ethics. In the practice of medicine, medical errors do occur. There is a fine line between error and negligence. This is an example of an often neglected aspect of medical teaching [10] which illustrates the need to define important clinical ethical issues that practitioners grapple with, and to ensure that these are systematically ingrained and taught. Training in medical ethics will provide such a framework with which to address the challenges encountered during practice. This will ensure that as problems which cannot be resolved simply by appealing to professional codes, science, religion, the law or even common sense arise, practitioners have the framework with which to resolve them.

\section{Methods}

\section{Study design and tools/guides}

This was a qualitative study carried out between May and August 2013. The study tools consisted of key informant interview (KII) and focus group discussion (FGD) guides.
The KII guide was used to interview academic administrators who had oversight for training and lecturers who taught ethics to medical students. This tool had both, closed and open-ended questions that allowed for further exploration of issues that arose during the interviews. Focus group discussions were held for both, the post-graduate and the undergraduate students which began with defining medical ethics to help ensure a clear understanding of the topic for discussion. This paper will focus solely on the teaching of undergraduate medical students.

The KII guide had questions on the understanding of the interviewees of medical or clinical ethics, and any policies or guidelines they were aware of that encouraged the teaching of ethics. It further sought to determine if medical ethics at the university had a specific fleshed out curriculum, when it was taught, how it was taught and which faculty were assigned the teaching. In addition, the specific training provided to those who taught ethics was elicited, and how many hours it was taught for and how it was examined. We further enquired if the administrators and lecturers felt that the amount of training was adequate, and if they had any further suggestions for how clinical ethics should be taught. They were also given an opportunity to share any additional comments or concerns they might have.

The FGD guides for students had similarly sought to understand the students' awareness of the definition of medical/clinical ethics and of any policies or requirements for the teaching of ethics. The discussion specifically asked the students if they had been taught medical ethics, and if so during which years of their training, what they learned about it, how the teaching was done and the designation and qualifications of the lecturers who had taught them. We further elicited their views on the adequacy of the teaching, their views on the competency of the teachers, the examination on the topic and if there were any changes they would have wished for. The students were provided with the opportunity to further comment and provide any suggestions for what they considered might enhance learning.

\section{Ethical considerations}

Approval to undertake the study was obtained from the ethics review committee of the Kenya Medical Research Institute (SSC 3537 dated May 24, 2013), and the Sindh Institute of Urology and Transplantation* (SIUT-ERC/ERC-A42013 dated February 2, 2013). In addition, permission was obtained from the relevant academic institutional/ organisational heads. Prior written informed consent was also obtained from all individuals who participated in the key informant interviews and the focus group discussions and a copy of the consent form was provided to all participants for their records.

\section{Data collection}

The data collection was limited to the first two universities 
to train medical doctors in Kenya: Moi University and the University of Nairobi [8] which are the only two recognised for reciprocity of training within the East African member states. This recognition allows those trained at these institutions to practice within the East African member states without additional testing for competency, after registration by the Medical board or council of the specific country.

The University of Nairobi, located in Nairobi - the capital city of Kenya, was the first medical school established in Kenya in 1967 [11]. With a student population of over 3300 and over 239 staff, it is the highest ranked university in Kenya [12]. Moi University School of Medicine, located in Eldoret town, was established in 1988, with the first student cohort admitted in 1990 [13]. Moi University Medical School has a population of over 300 students and 75 faculty (personal communication from the Dean, May 2013). Both are public universities.

\section{Key Informant Interviews}

All those contacted for interviews expressed willingness to be interviewed and appointments were thereafter made with the identified key staff holding administrative positions (eg Dean and/or Principal) and with the faculty who teach or coordinate the teaching of clinical or medical ethics who were identified by these administrators. All KII were held at the offices of the respective interviewees, as this was most convenient for them. All interviews were conducted in English and were audio recorded except for one where the interviewee asked for notes to be taken but did not consent to audio recording. All KII lasted between 20-45 minutes. Interviews were carried out in both the cities where the medical schools are located.

\section{Focus Group Discussions}

The FGDs were conducted in the cities where the two medical schools are located. The lecturers/administrators at the universities were asked to request willing medical students to attend the FGDs. At Moi University, the coordinator of the medical/clinical ethics course was the contact point for recruiting the participants. The coordinator contacted willing final year medical students and asked them to attend the FGDs at a prearranged time. At Nairobi University, the contact persons, were themselves medical students whose names were provided to the principal investigator (PI) by the Dean of students. These students contacted other willing students and invited them to attend the FGDs at the prearranged times. The FGDs included students from different years of study, but the majority who attended were in the final years of each training programme. All the FGDs were conducted by the principal investigator.

Each FGD had between 5 to12 participants and lasted between 1.5 to 2.15 hours. They were conducted in English, and each participant gave written consent for participation and for audio recording of the discussions. Light refreshments were provided at the FGD and participants were reimbursed their travel costs to the venue. Travel reimbursement was Kenya shilling 500 (6 USD).The FGDs were stopped once saturation was achieved with no new themes emerging.

Data from the KIIs and FGDs were recorded on an audio recorder and transcribed by the PI. Informed consent sheets and data informational sheets were kept in separate folders and in separate compartments of a locked filing cabinet in the PI's office.

The $\mathrm{PI}$ is female and was a student at the Centre for Biomedical Ethics and Culture at the Sindh Institute for Urology and Transplantation, Karachi, Pakistan. She was an Obstetrician Gynaecologist with public health training (PhD level), had previous training in research ethics from the University of Cape Town, South Africa. She had no prior relationships with the participants. As a Master's student in public health at the University of Washington, she had taken classes in qualitative research methods. She had also been involved previously in epidemiological clinical and sociobehavioural research.

\section{Data analysis}

The socio-demographic data of the participants and their affiliated institutions are presented as simple descriptive statistics. The audio recordings were transcribed for each KII and for each FGD. The transcripts from both the FGDs and KII were read and explored several times by the PI to identify cross cutting and emerging themes from the discussions. Main and sub themes which captured the spirit and essence of the FGDs and KII were identified and grouped as per different groups of participants - administrators and teaching faculty, and undergraduate medical students. Quotes that aptly captured the emerging themes were identified and highlighted and the most clearly illustrative chosen for inclusion.

\section{Results}

\section{The university approved curricula for medical students}

Both universities had approved curricula for the training of medical doctors based on the curriculum provided by the KMPDC [6]. One university's curriculum did not identify clinical/medical ethics as a separate subject to be taught but "ethics" was included during the teaching of other units which comprise the first two years of the 6-year programme. In 2013, there were no specified books or texts recommended or used for the teaching.

The other university identified ethics as a specific subject, and taught ethics in the first year under 'Behavioural Sciences and Introduction to Ethics', and in the final year as 'Medical Ethics and Medico-Legal Issues'. The final year at this university was taught using a specific course book, a copy of which was provided to all students (the availed version was dated July 2012, reprinted June 2013 by the College of Health Sciences' printing unit).

At both universities, ethics was not examinable as a core subject, but was examined within the other core disciplines. 
There were no lecturers identified as having been trained specifically in clinical/medical ethics by either the administrators, the lecturers or the medical students, but both the medical students and lecturers indicated that those teaching had some interest in ethics.

\section{Socio-demographic information}

\section{Lecturers}

A total of ten individuals (age range: $51-66$ years) were interviewed from the two universities, 6 from one and 4 from the other. Those in administrative positions (dean/principal) had served in that role for between 3-6 years. Those teaching had held those positions for between 10-33 years. The minimum qualification for teaching faculty was a Masters' degree. Those with initial training in medicine had done a Masters' in either internal medicine, psychiatry, or obstetrics and gynaecology. Others with training in medical sciences (eg biochemistry) or pharmacy had PhD level training. A majority $(8,80 \%)$ of those interviewed were male. None had formal training in bioethics or clinical ethics.

\section{Undergraduate students}

A total of 35 undergraduate students attended four FGDs: 20 from one university and 15 from the other. The average age of students from one university was 25.45 (range: 20-26) years. The majority were in the final year, with only one from the second year and two from the 4th year of training. The average age of the students from the other university was 27.46 (range: $25-30$ ) years. All were in the final year of training. There were a total of 11 (31\%) female students among the 35 participants; 6 of 15 (40\%) at one institution and 5 of 20 (25\%) at the other institution.

\section{Themes identified}

\section{Theory versus practice of ethics education}

The first emerging theme was that of ethics being taught in a theoretical manner but not evident in daily clinical practice. Each university had an approved curriculum that listed some aspects of clinical/medical ethics to be taught, and the lecturers and undergraduate students in both the Kenyan institutions trained in medicine indicated that 'some' aspect of ethics was taught. Ethics was taught as an introductory course in the first or second year of training of the behavioural science courses, and thereafter, it was up to the individual lecturers to decide if they wanted to include any additional ethics teaching in their courses. As a result, the teaching of medical/clinical ethics was not systematic or consistent throughout the major part of the clinical years.

Some teaching faculty felt that there was a clear attempt to ensure that medical/clinical ethics was taught during the course of teaching.

But I believe that as we teach, there are certain ethical principles that we try to impart in the practical aspect of the theoretical course that they did earlier. (KII)
Other teaching faculty realised that there were shortcomings in the teaching.

You know procedures...... giving people opportunity to make choices. And helping them to understand why we do things and why we may not do them and what options they have. If I understand it [ethics] to mean that, then I think we are not giving it enough...enough attention and I say that because, I think it is related also to communication skills. I think we do very poorly on that. Extremely poorly in fact I think this is going to be the next flash point for litigation... (KII)

The medical students indicated that there was a serious gap between the principles taught in the curriculum and what was actually taught in practice.

The consultants ask ... what is the diagnosis? What are you going to do about it... they do not have time to listen or to make any comments about ethics. (FGD)

Undergraduates and teaching faculty expressed concern over not getting adequate information on consequences or expectations, as not enough was taught on the legal aspects of medicine. This aspect of medicine has become increasingly important as the social standing that doctors once held in the community is dwindling, there is a rising awareness of litigation in the public domain; and this is not reflected in more systematic teaching of ethical behaviour.

That is one aspect that we feel we have a shortcoming, that we do not do enough....... perhaps we need to get legal minds to engage.... and legal specialists .........it is an area that we need to emphasize... anything we do, they need to think of what the legal consequences are. (KII)

\section{Lack of attention in teaching ethics}

There was a consensus among administrators, lecturers and medical students that there was insufficient emphasis on the teaching of clinical/medical ethics across the board. All interviewed parties agreed that medical students are under pressure to learn, and since students want to pass examinations, the topic which is not examined is most likely not given much attention. Despite this, everyone [undergraduates and lecturers] unanimously agreed that medical ethics is an important subject.

Medical ethics is a terribly important subject and must be taught well... The weeks we have to teach this is not exhaustive... there is not enough time to teach... There are many emerging new things that come up that were not thought of when the course was set up. (KII)

There was an awareness among the teaching faculty that because of the load of reading required during medical school, students weighed what they needed to give attention to. 
When they look at it and see it is only one or two units and likely not to contribute to the overall passing or failing, they will ignore it. (KII)

At one university, ethics was taught within various departments and within various subjects, followed by an examination on ethics. The questions on ethics were few and interspersed within the general examination of the other medical disciplines. In the second university, an $80 \%$ attendance was required for the tutorial discussions on ethics, but without a specific examination on the subject of ethics. The students felt that the priority given to training on ethics was not high, so they did not value these teachings at this stage, and they did not prioritise it. The students focused on the subjects which they had clarity on what was required.

I focus on medicine, psychiatry and surgery which will make me pass... I will not think about the CAT [continuous assessment test] in forensic pathology which has ethics... it will contribute very little to my final passing. (FGD)

The eyes cannot see what the mind cannot see.... the system has failed, we do not even know the framework... we do not even know if it is a legal requirement for us to learn ethics.... It is not being taught well .... My colleague knows what he needs to know in surgery...but he does not know what he needs to know in ethics... and he cannot quantify it... (FGD)

Anatomy has 9 units and ethics has 0 units.... It is clear what one will focus on. (FGD)

The students expressed that there was a disconnect between the teaching in the early years and the teaching in the final year of training. There seemed to be a rush during the final year to teach what needed to be taught but had not been covered throughout the previous years.

They jump second and third year and then bring it [Ethics] in fifth year... to find my notes from those years.... they even get lost... and many of us synthesize knowledge when exams are close... you rearrange the knowledge and it makes sense, since there are no exams... no one pays it attention... and it is clouded by other topics... like anatomic pathology and post mortems ........ and then the classes are not well attended... whoever put the training in 2 and 5 year did not serve us well. (FGD)

It is like then you are taught [ethics] like a 'bolus dose' like you must know everything before you leave. (FGD)

\section{Lack of role modelling}

The third theme that emerged was that of a lack of role models that set standards for the students to emulate. Leading by example was noted by the administrators and teaching faculty to be a challenge. The lack of mentorship was in part thought to be due to lack of training in bioethics for faculty assigned to teach and also the physical availability of those designated to teach, due to other competing interests and demands on their time.
We need more mentorship than that is currently available... and for you to mentor someone.... you need to be available.... The back ground of the ethical issues is because someone is rushing to go [elsewhere]. (KII)

The amount of time the teaching faculty spent with the students and the choices and clinical decisions were of concern to both the students and the teaching faculty. These lecturers realised that they had an opportunity to influence the students, but leading by example was identified as an important part of training which was difficult to achieve. The medical students similarly indicated that the consultants seem to be more concerned with medical diagnosis and treatment of the patients but did not emphasise the "softer skills" and overall medical care which are the aspects of medical practice central to medical ethics. These softer skills include aspects of good communication with patients, appropriate bedside mannerisms and how to communicate with both peers, senior colleagues and other hospital staff. Because of the high work load, there was a sense that there was not enough time for detailed explanations to students or to share the treatment plan with the patient.

In the hospital... it is about moving the queue so you hardly ever get to see the consultants show you how to do anything. (FGD)

Perhaps it is because we have many patients and the consultants are not there all the time....... the consultants seem to focus on the pathology and the treatment, but they do not seem to be concerned about the social aspects or any ethical concerns. (FGD)

While there was willingness to teach if asked, the consultants would not necessarily volunteer to teach clinical/ medical ethics because of the pressure of work or other demands on their time, or because there was no recognition of the need to teach medical ethics. Students noted that even when ethical challenges and dilemmas occurred, they were not converted into opportunities to engage with the students and enable them to learn best practices.

When there is a special need or an ethical matter, it is referred to someone else or the social workers or the psychiatrist and the medical students do not get to deal with it or to participate in the understanding of how to handle it. (FGD)

As there was no particular system put in place to ensure lecturers and consultants provided models of ethical behaviour, students identified for themselves individuals who were good role models based on their keenness to teach ethics and their behaviour towards patients during clinical ward rounds.

Some of the consultants try hard and a few of them focus on the whole patient, it is not a general requirement, it is personal initiative dependent on the consultant. (FGD) 
There are some ethical doctors... like ward I was in... it was the first time I saw lumbar punctures done under local anaesthesia.... And he ensures that patients are counselled before they start chemotherapy... so they are some positive role models. (FGD)

Medical students also modelled their behaviour on the postgraduate students whom they spent most of their time with during clinical work. They therefore may have learned whatever these postgraduates had in turn learned during their undergraduate year or perhaps benefitted from the personal qualities of these doctors.

\section{Lack of training in communications skills}

Lecturers and undergraduate medical students alike admitted to challenges in the teaching of communication skills, noting that this was either not taught or not taught well, and was further compounded by the lack of senior role models to show them how to communicate well:

If I look at medical ethics to encompass provider and participant interaction meaning communicating procedures giving people opportunities and choices, getting people to understand what we do and why we do it.... Then we are not giving it enough attention. ..... I say that because it is related to communication skills and we do very poorly, very poorly, it will be the next flash point for litigation. (KII)

Students indicated that they needed to be able to learn communication skills as this would enable them to work effectively, eg by delivering bad news to patients and/or explaining complex medical issues in a way patients would be able to understand before consenting to treatment plans.

Beyond breaking bad news, there is just the matter of communicating with patients... a doctor will examine a patient and never inform him of what has been found. (FGD)

The nature of the patients we have also makes it difficult... if someone does not have a good understanding of the language or the issues......no one has time to talk to the patient and they say.... Get the consent and put the patient on the list... they should sit with the consent form and let you hear how the whole process should be done.... someone undergoing an extensive procedure.... Someone should explain... we never get to see how that happens. If it is the ward round where the decision is made and the next time we see the patient in the theatre with the signature in the right place.... we need to see how they handle the questions and the concerns the patients would have. (FGD)

Without examples or mentorship, the medical students admitted that they passed the responsibilities to others when they were not able to adequately handle the challenges with communication.

\section{Discussion}

Developing countries like Kenya still face critical issues in their healthcare systems. We found that university administrators, lecturers and undergraduate medical students in the two oldest medical schools agreed that the teaching of medical/clinical ethics falls short of their needs or expectations. The main themes identified were the lack of attention paid to the teaching of medical ethics, the gap between the theory taught versus what they saw in practice, a lack of role models from among the lecturers, and inadequate training in communication skills.

\section{Theory versus practice of ethics education}

The gap between the theory taught to the students compared to what they experienced in practice during rounds can be in part attributed to the lack of formal texts and references used during the training, among other reasons. In addition, the lack of formal training of those who teach, specifically, in bioethics or medical ethics as an additional competency may further contribute to this gap. The Commission of University Education (CUE) approves all curriculums in institutions of higher education and has recently taken up reviews at universities to ascertain that standards are being met [14]. Teaching of ethics was also not consistently done throughout the years, which presented students with concerns by the time they were exposed to practical rounds. Then they had little to no knowledge of clinical ethics, or had forgotten what had been taught in the previous years. And when this is not consciously incorporated into the practical bedside teaching, then the opportunity to put the theory into practice is lost. This was also the case in an observation of ethics education in a South African medical school [15]. The solution presented there was to incorporate different ethics modules throughout the medical school years and have assessments based on the theory taught and what was observed in the clinical rounds [15].

Medical education in Africa is not a level playing field compared to the more developed countries [16], as many "givens", eg political and financial instability and provisions of the tools or the infrastructure to support the healthcare worker are not always easily available. Therefore, ethical principles are applied differently in these environments, and lecturers should ensure teaching is comprehensive enough to include application of the principles and not just theoretical concepts. It is imperative that the practice of medicine be made more effective and ethical in resourcestrapped environments. It is important to teach students the principles of ethical behaviour in contexts where the students can engage, debate, question and have examples of how to apply these in the environments in which they will practise medicine $[9,15]$.

Lack of attention in teaching ethics and role modelling 
These two themes are discussed together as the factors contributing to both have some similarities. Those who were teaching bioethics lacked formal training in ethics education. It was not clear if they teach out of passion for the subject or from not having a choice if the topic was allocated to them. In many settings, teachers/lecturers tend to model the teaching method they were taught, incorporating what worked or didn't work for them into their own teaching styles [17]. Without formal teaching and because of the heavy workload and limited time, it is easy for ethics to be overlooked in favour of other subjects in the medical curriculum that have more extensive content and are examinable. However, if a subject was one in which a lecturer had some personal interest, it may be that they would put in more effort. This, however, was not demonstrated in our findings.

The brain drain has caused human personnel in the healthcare sector to be outnumbered by the rising volume of patients $[4,18]$. The uneven doctor to patient ratio overburdens lecturers, which can account for the lack of role models and attention given to teaching in medical schools in resource-limited settings. Many physicians also work in private hospitals to supplement their incomes [18] and these part-time jobs have implications, eg for the amount of preparation given to lectures and how the students are taught during their clinical ward visits. Thus increasing the number of doctors alone may not totally address the healthcare needs or offset the structural forces at play in the provision of healthcare in low- and middle-income countries such as Kenya [18]. Additionally, students can learn from both negative and positive role models. Students may adopt the unprofessional behaviour of negative role models leading to a learned insensitivity (19). However, these negative role models can also provide a learning of the behaviour one should not exhibit towards patients.

\section{Lack of training in communication skills}

Despite designated teaching in ethics, the aspect of communication was still not felt to be comprehensively taught or presented at an optimum time, that is before the students begin, or during, their clinical wards rounds or senior clerkship.

This aspect of communication has a direct bearing on clinical practice since the educational level of patients and their ability to understand sometimes complex medical terms or procedures raises concerns. One concern is whether the consent obtained from patients is really valid [20]. Often, patients do not understand the procedure they are about to undergo and they have no opportunity to ask questions or have their condition explained in a language of their choice $[15,20]$. In addition, a need is expressed for doctors to be kinder, more courteous, gentle and not be rude to optimise the patient-doctor relationship [15]. This is particularly important as an ethical issue given the imbalance of power in a clinical encounter which makes patients vulnerable.
Given the changing social environments, doctors too are gaining awareness of their rights and powers, which in the recent past resulted in a country-wide labour strike in Kenya. This, termed as medical disruption [15] poses challenges on how to navigate ethical dilemmas centred around providing care, doing no harm (such as may be caused by lack of service delivery during a labour strike) and for justice to both patients and healthcare workers. Communication from the doctors to the patients, to colleagues and those in authority remains a core skill needed for everyday functioning and to resolve complex human resource and welfare matters.

While there is no one right way to resolve these dilemmas, having discussions about them can lead to strengthening of problem-solving abilities in students whenever they face such challenges. Ethics education would allow students the ability to integrate, interpret and apply knowledge to ethical dilemmas as they arise during their subsequent years in medical practice [15].

\section{Limitations}

During data collection, a written curriculum of the training with details of what is taught and when, was not made available, and thus, the investigator relied on the information received during interviews which would have reflected the interviewees' bias.

The investigator depended on administrators for contacts which yielded the final group of participants and interviewees, and if there was bias in selecting those, this could have influenced the findings. Referrals of students interviewed was also on a "snowball" basis and so this could have captured only the views of a segment of like-minded students.

In addition, having been trained at one of the institutions and feeling that the subject of clinical ethics was not adequately taught during my time, it is possible that this bias may have coloured the framing of the questions. However, every attempt was made to keep the questions neutral during the interviews and focus group discussions. The lecturers, who were similar in demographics and training to the investigator, expressed similar concerns to those of the students, thus providing some validation for the findings.

\section{Conclusion}

Medical ethics is an important aspect of medical teaching. The identified gap between what is in the curriculum, the theory and the practice of ethics is important to address. Several practical steps can be taken towards this.

Formal training for those who are designated to teach this subject would be important. In addition, some aspects of ethics should be included in every year of medical school and it should be an examinable subject to give it the 
seriousness it merits. The recognition of medical ethics as a valid subspeciality in medicine would also be important.

In addition, the identification of textbooks for use, and encouragement of the development of material suitable to this specific context and settings should be encouraged. We also recommend that the methods of teaching should be strengthened and incorporated into clinical settings to enable students who graduate with experience in moral reasoning for resolving ethical dilemmas.

Lastly, enabling good mentorship and good role modelling, and providing resources would also be a step in the right direction to produce the next generation of not just competent but compassionate medical practitioners. The resources to achieve this may include, but not be limited to the training of those teaching ethics, the recognition of bioethics as a subspeciality within medical practice and the use of reading and reference materials for teaching.

\section{Acknowledgements}

*This study was done as part of Elizabeth Bukusi's Masters in Bioethics requirements at the Sindh Institute of Urology \& Transplantation (SIUT) in Pakistan. Professor Bukusi's training was funded by a European and Developing Countries Clinical Trials Partnership grant (CB.2010.41302.016) whose objective was to restructure and strengthen the process of ethics review at the Kenya Medical Research Institute, which is one of the leading research institutes in sub-Saharan Africa.

The author wishes to thank Professors Farhat Moazam and Aamir Jafarey who supervised the MBE thesis, Timothy Kipkosgei who supported the data collection, Sarah Okumu, Rachel Mwakisha and Petronilla Njenga for their support in administration and logistics.

Conflict of Interest: None declared.

\section{References}

1. Kenya Law. Act No. CAP 253 Act Title: Medical Practitioners and Dentists. 2019 [cited 2020 Apr 14]. Available from: http://kenyalaw.org: 8181/exist/kenyalex/actview.xql?actid=CAP.\%20253

2. Greek Medicine - The Hippocratic Oath. U.S. National Library of Medicine; [cited 2020 Apr 14]. Available from: https:// www.nlm.nih.gov/hmd/greek/greek_oath.html

3. Jhala $\mathrm{Cl}$, Jhala KN. The Hippocratic oath: A comparative analysis of the ancient text's relevance to American and Indian modern medicine. Indian J Pathol Microbiol. 2012 Jul 1;55(3):279.

4. Coleman AME. Medical Ethics and Medical Professionalism in Low and Middle Income (LAMIC) Countries: Challenges and Implications. Bangladesh J Bioeth. 6(2):1-7.

5. The Republic of Kenya, The Code of Professional conduct and discipline. 6th Edition. Kenya Medical and Dental Practitioners Board. [cited 2020 Apr 4]. Available from: https://kmpdc.go.ke/ resources/Code-of-Professional-Conduct-and-Discipline-6thEdition.pdf

6. Medical Practitioners and Dentists Board. Bachelor of Medicine and Bachelor of Surgery Core Curriculum. Date unknown [cited 2020 Sep 11]. Available from: https://kmpdc.go.ke/resources/mbchb.pdf

7. Commission for University Education. Standards and Guidelines for University Academic Programmes. Nairobi, Kenya. 2020 [cited 2020 Sep 11]. Available from: http://www.cue.or.ke/index.php/downloads/ category/16-standards-and-guidelines

8. Kenya Medical Practitioners and Dentists Council. Undergraduate Training. 2020 [cited 2020 Sep 11]. Available from: https:// kmpdc.go.ke/undergraduate-training/

9. Boyd K. Questioning previously accepted principles. J Med Ethics. 2018 Sep;44(9):583-4.

10. Rosner F, Berger JT, Kark P, Potash J, Bennett AJ. Disclosure and Prevention of Medical Errors. Arch Intern Med. 2000 Jul 24;160(14): 2089-92.

11. University of Nairobi. Brief History | School of Medicine. 2019 [cited 2020 Sep 11]. Available from: https://med-school.uonbi.ac.ke/ index.php/basic-page/brief-history

12. UniRank. Top Universities in Kenya. 2020 Kenyan University Ranking. [cited 2020 Sep 11]. Available from: https://www.4icu.org/ke/

13. Moi University. About Us - School of Medicine. 2019 [cited 2020 Sep 11]. Available from: https://som.mu.ac.ke/index.php/about-us

14. Commission for University Education. Standards and Guidelines for University Programmes. 2017 [cited 2020 Sep 11]. Available from: http://www.cue.or.ke/index.php/downloads/category/16standards-and-guidelines\#

15. Moodley K. Teaching medical ethics to undergraduate students in post-apartheid South Africa, 2003 - 2006. J Med Ethics. 2007 Nov 1;33(11):673-7.

16. Gibbs T. Medical education in Africa: not always a level playing field. Med Teach. 2007 Jan;29(9-10):853-4.

17. Chung E-K, Rhee J-A, Baik Y-H, A O-S. The effect of team-based learning in medical ethics education. Med Teach. 2009 Jan;31(11): 1013-7.

18. Donatus G. Ethical issues in health care in Kenya. A critical analysis of healthcare stakeholders. Res J Finance Account. 2011;2(3):19.

19. Wolf G. Portrayal of negative qualities in a doctor as a potential teaching tool in medical ethics and humanism: Journey to the End of Night by Louis-Ferdinand Celine. Postgrad Med J. 2006 Feb 1;82(964):154-6.

20. Ochieng J, Buwembo W, Munabi I, Ibingira C, Kiryowa $H$, Nzarubara $\mathrm{G}$, et al. Informed consent in clinical practice: patients' experiences and perspectives following surgery. BMC Res Notes. 2015 Dec;8(1): 765 . 